\title{
Clinicopathological Profiling of LC3B, an Autophagy Marker, and ESRRA (Estrogen-related Receptor-alpha) in Muscle-invasive Bladder Cancer
}

\author{
SUP KIM ${ }^{1,2,3,4^{*}}$, ADAM JAEHYEOK LEE ${ }^{*}$, MIN-KYUNG YEO ${ }^{1}$, YONG GIL NA ${ }^{6}$, JI-YEON KIM ${ }^{5}$, \\ MOON-JUNE $\mathrm{CHO}^{4}$, JUN-SANG KIM ${ }^{4}$, EUN-KYEONG JO ${ }^{2,3}$ and JIN-MAN KIM ${ }^{1,3}$ \\ ${ }^{I}$ Department of Pathology, Infection Control Convergence Research Center, \\ College of Medicine, Chungnam National University, Daejeon, Republic of Korea; \\ ${ }^{2}$ Department of Microbiology, Infection Control Convergence Research Center, \\ Chungnam National University, Daejeon, Republic of Korea; \\ ${ }^{3}$ Department of Medical Science, College of Medicine, Chungnam National University, Daejeon, Republic of Korea; \\ ${ }^{4}$ Department of Radiation Oncology, College of Medicine, \\ Chungnam National University, Daejeon, Republic of Korea; \\ ${ }^{5}$ Department of Surgery, College of Medicine, Chungnam National University, Daejeon, Republic of Korea; \\ ${ }^{6}$ Department of Urology, College of Medicine, Chungnam National University, Daejeon, Republic of Korea
}

\begin{abstract}
Background/Aim: Microtubule-associated protein 1 light chain $3 B(L C 3 B)$, an autophagy marker, has been used as a promising marker in various cancer types. However, the expression of LC3B in muscle-invasive bladder cancer (MIBC) and its prognostic significance have not been investigated. Recent studies pointed to the involvement of ESRRA in regulating autophagy via both transcriptional and posttranslational control. In the current study, prognostic importance of $L C 3 B$ and ESRRA in MIBC was investigated. Patients and Methods: We immunohistochemically studied the expression of LC3B and ESRRA in 56 MIBC samples. Results: $L C 3 B$ was stained high in 16 patients (28.6\%) and low or negative in 40 patients (71.4\%). ESRRA expression was high for 20 patients (35.7\%) and low for 36 patients (64.3\%). Both LC3B $(p=0.003)$ and ESRRA $(p=0.026)$ expression correlated significantly with disease-free survival rates. Double-positive $L C 3 B$ and ESRRA correlated with poor overall survival $(p=0.007)$ and disease-free survival $(p=0.001)$ in MIBC
\end{abstract}

\footnotetext{
*These Authors contributed equally to this work.

Correspondence to: Jin-Man Kim, Department of Pathology, Infection Control Convergence Research Center, College of Medicine, Chungnam National University, 266 Munhwa-Ro, Junggu, 301747 Daejeon, Republic of Korea. Tel: +82 425808231, Fax: +82 422807189, e-mail: jinmank@cnu.ac.kr
}

Key Words: Muscle-invasive bladder cancer, autophagy, microtubuleassociated protein 1 light chain $3 \mathrm{~B}$, estrogen-related receptor-alpha. prognosis. patients. Conclusion: LC3B and ESRRA might be a useful prognostic factor in patients with MIBC. The co-expression of LC $3 B$ and ESRRA might be a prognostic and therapeutic target for patients with bladder cancer.

Bladder cancer is a common malignant tumor of the genitourinary tract (1). In patients with bladder cancer, muscle-invasive bladder cancer (MIBC) accounts for $30 \%$ of newly diagnosed bladder cancer, and shows rapid progression to metastatic disease and increases patient mortality. Furthermore, $50 \%$ overall survival at 5 years has remained relatively unchanged in 20 years $(2,3)$. Therefore, identifying novel molecular targets and improving treatment response to current treatment regimens may overcome treatment failure.

There is accumulating evidence that autophagy plays an important role in urinary bladder cancer. Compared to normal urothelial tissue and low-grade urothelial carcinoma, high-grade urothelial cancer showed increased number of autophagic vesicles and expression of autophagic proteins (4). Additionally, autophagy pathway inhibition by siRNA or inhibitors increased cell death and chemotherapy-induced cytotoxicity in bladder cancer cell lines $(4,5)$. Furthermore, studies using bladder urothelial tumors and normal urothelial specimens showed a significant correlation between Bcl-2 levels and both histologic grade and pT stage via antiapoptotic pathways. These results imply a role for autophagy-related pathways in the progression and aggressiveness of bladder urothelial tumors, because Bcl-2 is well known as an autophagy inhibitor through binding to Beclin-1 (6-8). Based on these studies, it may be assumed 
that autophagy-related genes (ATGs) or autophagy regulators are potential targets in bladder cancer therapy.

Substantial studies have so far focused on identification of many ATG genes that are essential to regulate and implement the autophagic process. Currently, more than 30 ATG genes have been discovered in yeast and many of them have also been found in humans $(9,10)$. Among these, microtubule-associated protein 1 light chain 3 (LC3) is a specific marker of autophagosomal formation and is the most widely expressed gene in autophagy-related studies $(11,12)$. In mammals, there are three isoforms of LC3; A, B and C. Because of broad tissue specificities, the B isoform, LC3B, is most commonly used for autophagy assays (13). Although a great deal of research has focused on the molecular mechanism of transcription activation of ATGs including LC3B, little progress has been reported. Recently, our study reported that estrogen-related receptor- $\alpha$ (ESRRA) is involved in the transcription of several autophagy genes including anti-microtubule-associated protein 1B-light chain 3 (LC3B), autophagy protein 5 (ATG5), BECN-1, and so on (14). These studies led us to hypothesize that ESRRA may play a role in enhancing bladder cancer progression through its role in autophagy. Therefore, we aimed to evaluate the expression and clinicopathological significance of ESRRA and LC3B in bladder cancer, which could provide an innovative idea for further study of biomolecular mechanisms in a therapeutic setting.

\section{Materials and Methods}

Patients selection and tissue microarray construction. We initially retrieved, from our surgical pathology files, 84 cystectomy specimens performed at Chungnam National University Hospital from 1999 to 2010. All sections were reviewed for confirmation of the original diagnosis by a pathologist on the study and staged according to the 2010 American Joint Committee on Cancer-TNM classification. Of the 84 samples, 67 were qualitatively and quantitatively suitable for immunohistochemistry (IHC). Patients who died of treatment-related causes $(n=7)$ or who were classified as stage T1 $(n=4)$ were excluded. The clinicopathologic characteristics of the 56 patients who were still alive at the end of the study or had died of bladder cancer are listed in Table I. The median age was 73 years (range=37-86 years) with a male:female ratio of 5:2 (47/9). The pathologic T stage (TNM version 7) were pT2 $(n=30)$ and pT3, $4(n=26)$. The pathologic $N$ stages (TNM version 7) were $\mathrm{N}(-)(\mathrm{n}=53)$ and $\mathrm{N}(+)(\mathrm{n}=3)$. The pathologic TNM stages (TNM version 7$)$ were stage II $(n=29)$ and stage III-IV $(n=27)$. Tissue microarray were constructed using a manual tissue arrayer (Chemicon ATA-100, California, USA) using 2-mm cores. Two representative cores from each donor block were selected with hematoxylin and eosin-stained sections. This study was approved by the institutional review board of Chungnam National University Hospital (IRB No. 2017-02-036).

Clinicopathological variables and patient follow-up. Variables were grouped in the following 2 categories: clinical and pathologic. Clinical variables included the following: (1) patient's age (in
Table I. Characteristics of the patients with muscle-invasive bladder cancer.

\begin{tabular}{lcc}
\hline Characteristics & Frequency & $(\%)$ \\
\hline Gender & & \\
$\quad$ Male & 47 & $(84)$ \\
Female & 9 & $(16)$ \\
Age, years & & \\
$\quad \leq 70$ & 7 & $(13)$ \\
$\quad>70$ & 49 & $(87)$ \\
Tumor invasion & & \\
pT2 & 30 & $(54)$ \\
pT3,4 & 26 & $(46)$ \\
Lymph node status & & \\
N0 & 53 & $(95)$ \\
N1-3 & 3 & $(5)$ \\
pTNM stage & & \\
II & 29 & $(52)$ \\
III-IV & 27 & $(48)$ \\
\hline
\end{tabular}

pT: Pathologic tumor stage; N: lymph node stage; pTNM: pathologic TNM stage.

years), and (2) patient's gender (male versus female). Pathologic variables in the primary tumor included the following: (1) pT stage at cystectomy (pT2 versus pT3, 4), (2) lymph node metastasis (N0 vs. N1-3), and (3) pTNM stage (II versus III-IV). IHC expression evaluation is described in the next paragraphs. Outcome variables included tumor recurrence and cancer death as the end points. "Event cases" included patients who showed tumor recurrence (i.e., locoregional recurrence or distant metastatic disease) or patients who died as a result of the cancer. "Censored cases" included patients in whom the end point was not observed or patients for whom data regarding the outcome status were not available in the medical records. Follow-up length extended from the date of cystectomy until the appearance of the event (for event cases) or date of data gathering (for censored cases). Patients were followed up for 4 to 185 months (median, 42 months).

LC3B/ESRRA immunohistochemistry and scoring system. Immunostaining using a 3,3'-diaminobenzidine peroxidase substrate kit (DAKO Cytomation, Inc., Carpinteria, CA, USA) was performed according to the manufacturer's protocol. Two primary antibodies were used: rabbit polyclonal anti-LC3B antibody (NB100-2220, Novus Biologicals, Littleton, CO, USA), and anti-ESRRA antibody (2ZH5844H, Perseus Proteomics Inc., Tokyo, Japan). Anti-LC3B (1:1600) and mouse monoclonal anti-ESRRA (1:200) antibodies were diluted, then incubated in a humid chamber at room temperature for $30 \mathrm{~min}$. Without any access to clinical information, two experienced pathologists (MKY and JMK) examined slides and assigned scores. The immunostaining of the tumor was divided into four grades based on the staining intensity and scored: score 0 , no staining; score 1 , weak; score 2 , intermediate; score 3 , strong. In cases of heterogeneous staining within samples, the higher score was chosen if $>50 \%$ of the cells showed a higher staining intensity. Cases with no staining and a score of 1 were categorized as a low expression group (LEG), whereas those with a score of 2 and 3 were categorized as a high expression group (HEG). 
Statistical analysis. SPSS 21.0 for Windows (SPSS Inc., Chicago, IL, USA) was used for statistical analysis of the data. Comparison between protein expression and patient data was performed using Pearson chi-square test $\left(\chi^{2}\right)$. Disease-free survival (DFS) and overall survival (OS) curves were generated using the Kaplan-Meier method. Then, comparison of curves was analyzed using the logrank test. A value of $p<0.05$ was considered to indicate statistical significance.

\section{Results}

Immunohistochemical expression of LC3B and ESRRA in patients with $M I B C$. Immunohistochemistry showed that LC3B was expressed in the cytoplasm and ESRRA was detected mainly in the nuclei, as well as in the cytoplasm. For LC3B, 16 of 56 patients $(28.6 \%)$ were in the HEG, and 40 patients $(71.4 \%)$ were in the LEG (Figure 1). For ESRRA expression, 20 of 56 with bladder cancer expressed ESRRA in tumor tissue, with a HEG rate of $35.7 \%$, whereas 36 patients could be categorized as LEG (Figure 2).

Correlation of $L C 3 B$ and ESRRA expression with clinicopathologic features of MIBC. Next, we correlated ESRRA and LC3B protein expression with clinicopathologic characteristics, including gender, age at diagnosis, tumor invasion, and lymph node status. High LC3B expression was correlated with pathologic T (Pearson $\chi^{2}=10.920, p=0.001$ ) and TNM stage (Pearson $\chi^{2}=9.791, p=0.002$ ) (Table II): present in $10.0 \%$ of pT2 patients and $50.0 \%$ of pT3, 4 patients, and present in $10 \%$ of stage II and $48 \%$ of stage III-IV patients. Additionally, high ESRRA expression was associated with gender (Pearson $\chi^{2}=4.475, p=0.034$ ) (Table III): present in $29.8 \%$ of male patients and $66.7 \%$ of female patients.

Effect of $L C 3 B$ and ESRRA expression on the survival of patients with $M I B C$. The median follow-up period was 42 months (range $=4-185$ months). The association between clinical parameters and survival rate was investigated using Kaplan-Meier curves and log-rank test. Kaplan-Meier survival analysis showed that the 5-year OS and DFS were $69.2 \%$ and $63.8 \%$, respectively (Figure 3A). OS and DFS were significantly shorter in patients with high LC3B expression ( $p=0.003$ and $p=0.001$, the log-rank test, respectively) (Figure 3B). In addition, patients with high ESRRA expression had a significantly poorer DFS than those with low expression ( $p=0.026$, the log-rank test) (Figure $3 \mathrm{C}$ ). Pathologic TNM stage was marginally correlated with overall survival (hazard ratio(HR), 2.565; 95\% confidence interval(CI), 0.875-7.523; $p=0.086)$. Sex, age, $\mathrm{pT}$ stage, and lymph node status did not present any significance as a prognostic factor for OS and DFS (data not shown).

Correlation between LC3B and ESRRA in patients with $M I B C$. As shown in Figure 4A, 9 of 20 patients (45.0\%) had high LC3B expression observed in high ESRRA expression tissues, whereas 29 of 36 patients $(80.6 \%)$ with low LC3B expression existed in low ESRRA expression tissues. According to the Pearson chi-square test, LC3B expression had a positive correlation with ESRRA in patients with bladder cancer (Pearson $\chi^{2}=4.114, p=0.043$ ) (Figure 4A). These 56 patients with bladder cancer were classified into 3 groups according to LC3B and ESRRA expression, as follows: group 1 with double LEG $(n=29)$; group 2 with either LC3B LEG/ESRRA HEG or LC3B HEG/ESRRA LEG $(n=18)$; and group 3 with double HEG $(n=9)$. Group 3 patients had a significantly poorer overall survival rate ( $p=0.007$, log-rank test) and DFS rate $(p=0.001, \log$-rank test) than other groups ( $p=0.007$ and $p=0.001, \log$-rank test, respectively), which is illustrated in Figure 4B.

\section{Discussion}

Although the MIBC treatment strategy is decided using clinicopathologic parameters, there is a discrepancy between clinical and pathologic stages (15). For this reason, high percentage of patients with MIBC experienced disease progression and unnecessary death (15). Therefore, considerable inaccurate staging at initial diagnosis has led to the need to identify a novel marker for treatment response and survival. Many studies are performed in an attempt to determine the prognostic factors in bladder cancer. IGFBP5, FGF7, NDN, SPOCK1, CEBPD, ZNF671, HSP90, GAB1 and GATA3 are markers that have helped evaluate the clinical relevance by IHC and statistically significant relationships with clinical outcome have been reported. These markers are involved in various pathways including tumor growth, immune destruction, cellular stress, apoptosis, and EMT (1623). However, there is no study evaluating autophagy-related proteins as a prognostic factor in bladder cancer by IHC. In the current study, we investigated the prognostic significance of LC3B and ESRRA expression in bladder cancer. Our results showed that high $\mathrm{LC} 3 \mathrm{~B}$ and ESRRA expression is associated with a decreased rate of DFS. Additionally, the group with double-negative expression of LC3B and ESRRA has a very good prognosis in comparison with other groups. These findings suggest that LC3B and ESRRA expression may be used as adverse prognostic factors for MIBC patients who underwent cystectomy. To our knowledge, this study is the first to show the predictive and prognostic significance of LC3B and ESRRA in bladder cancer.

In this study, high LC3B expression was associated with poor OS and DFS, which is consistent with the emerging role of autophagic proteins as a molecular link between autophagy and nutritional limiting condition. The dramatic switch from survival to death in response to autophagy pathway blockers has been observed in bladder cancer, especially high-grade urothelial carcinoma (H/G UC) cells 

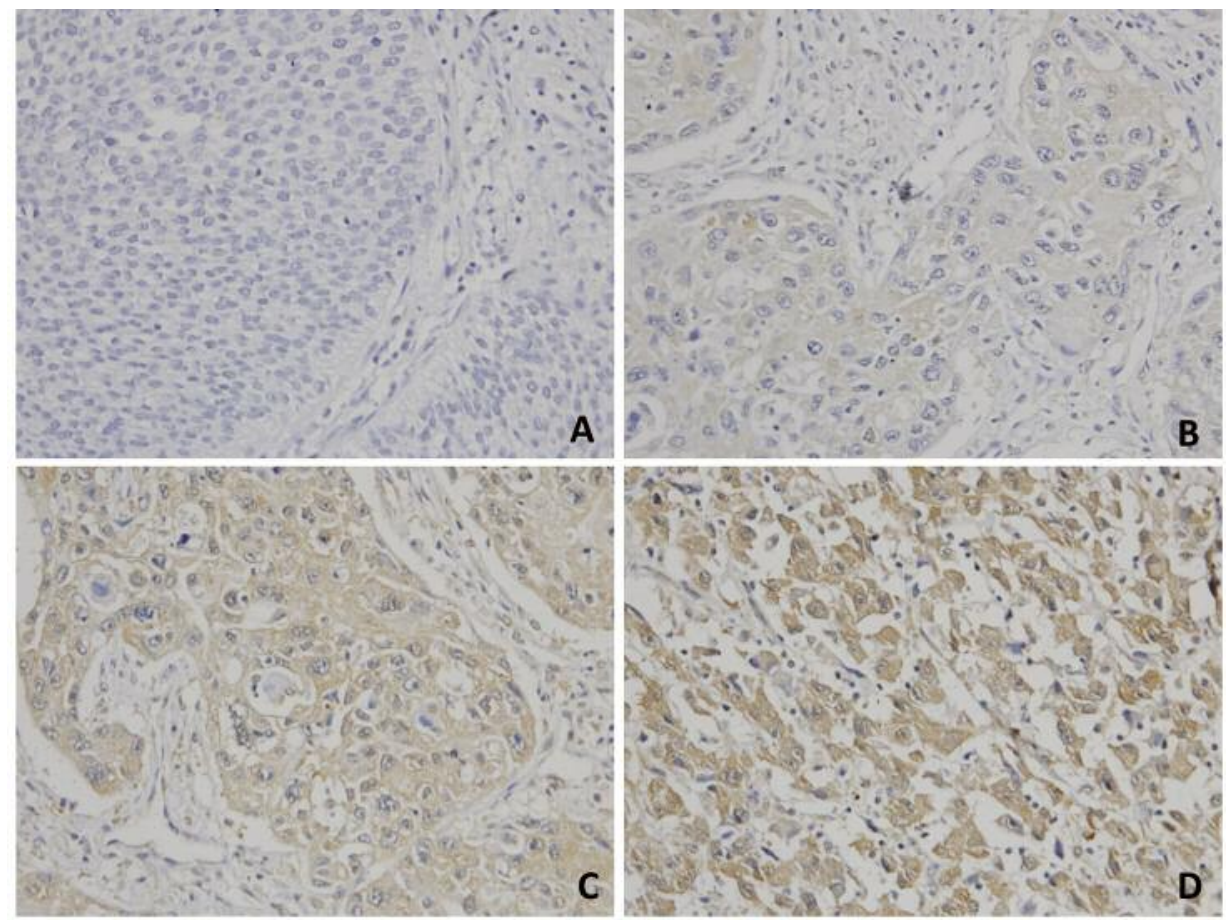

Figure 1. Representative photomicrographs of LC3B immunohistochemical staining in human bladder cancer tissues. (A) No staining intensity. (B) Weak staining intensity. (C) Moderate staining intensity. (D) Strong staining intensity (original magnification x400).
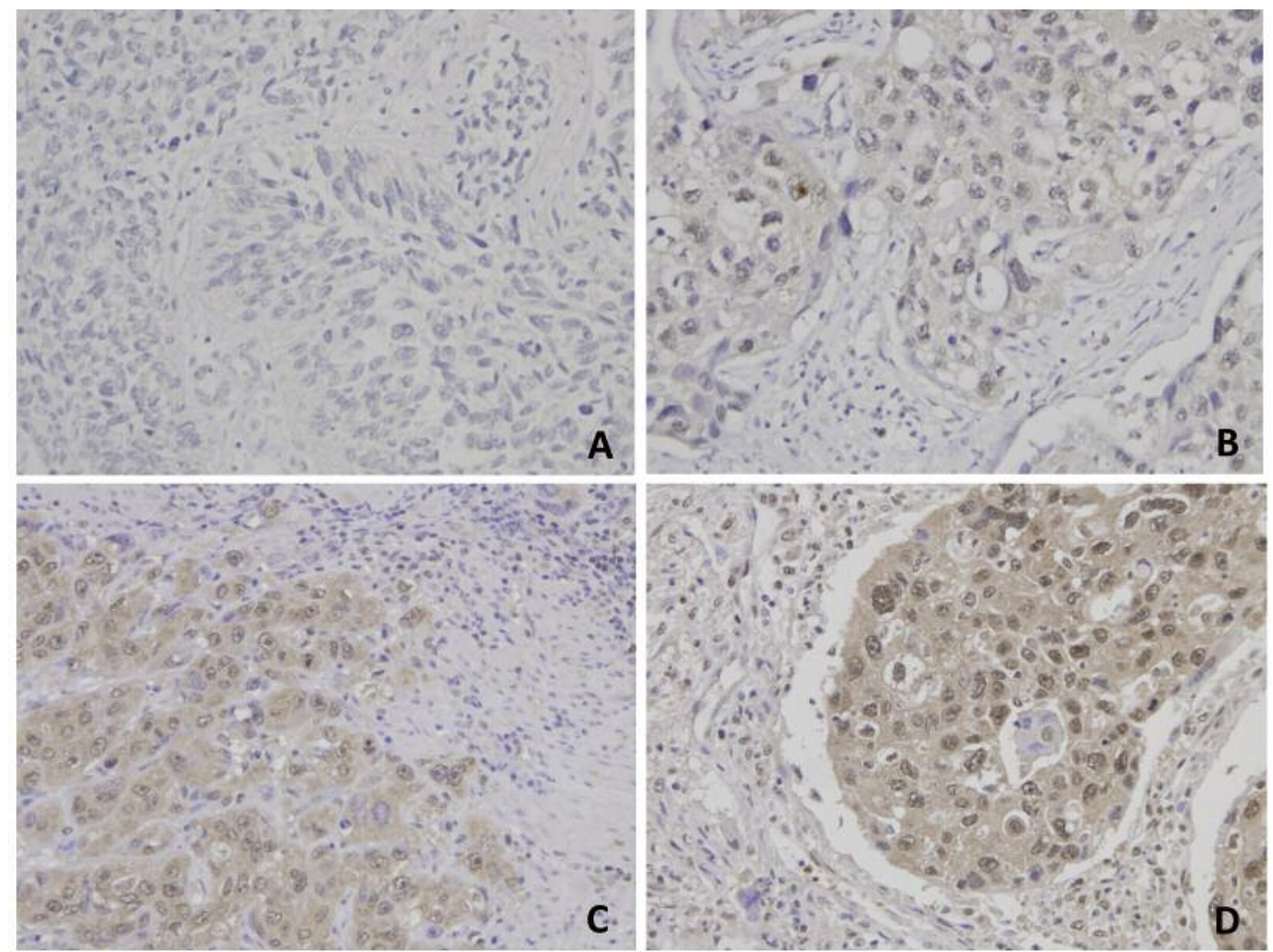

Figure 2. Representative photomicrographs of ESRRA immunohistochemical staining in human bladder cancer tissues. (A) No staining intensity. (B) Weak staining intensity. (C) Moderate staining intensity. (D) Strong staining intensity (original magnification $\times 400)$. 
Table II. Association of LC3B with clinicopathological features in bladder cancer patients.

\begin{tabular}{lcccc}
\hline Characteristics & $\begin{array}{c}\text { Total } \\
(\%)\end{array}$ & $\begin{array}{c}\text { LC3B } \\
\text { low } \\
\mathrm{n}=40(\%)\end{array}$ & $\begin{array}{c}\text { LC3B } \\
\text { high } \\
\mathrm{n}=16(\%)\end{array}$ & $p$-Value \\
\hline $\begin{array}{l}\text { Gender } \\
\text { Male }\end{array}$ & $47(84)$ & $33(82)$ & $14(87)$ & 0.645 \\
$\quad \begin{array}{l}\text { Female } \\
\text { Age, years }\end{array}$ & $9(16)$ & $7(18)$ & $2(13)$ & \\
$\quad$ 70 & $7(13)$ & $6(15)$ & $1(6)$ & 0.371 \\
$\quad 70$ & $49(87)$ & $34(85)$ & $15(94)$ & \\
Tumor invasion & & & & \\
$\quad$ pT2 & $30(54)$ & $27(67)$ & $3(19)$ & 0.001 \\
pT3,4 & $26(46)$ & $13(33)$ & $13(81)$ & \\
Lymph node status & & & & \\
$\quad$ N0 & $53(95)$ & $38(95)$ & $15(94)$ & 0.851 \\
$\quad$ N1-3 & $3(5)$ & $2(5)$ & $1(6)$ & \\
pTNM stage & & & & \\
$\quad$ II & $29(52)$ & $26(65)$ & $3(19)$ & 0.002 \\
III-IV & $27(48)$ & $14(35)$ & $13(81)$ & \\
\hline
\end{tabular}

LC3B: Microtubule-associated protein 1 light chain 3B; pT: pathologic tumor stage; N: lymph node stage; pTNM: pathologic TNM stage.

Table III. Association of ESRRA with clinicopathological features in bladder cancer patients.

\begin{tabular}{|c|c|c|c|c|}
\hline Characteristics & $\begin{array}{c}\text { Total } \\
(\%)\end{array}$ & $\begin{array}{c}\text { ESRRA } \\
\text { low } \\
\mathrm{n}=36(\%)\end{array}$ & $\begin{array}{c}\text { ESRRA } \\
\text { high } \\
n=20(\%)\end{array}$ & $p$-Value \\
\hline \multicolumn{5}{|l|}{ Gender } \\
\hline Male & $47(84)$ & $33(92)$ & $14(70)$ & \multirow[t]{2}{*}{0.034} \\
\hline Female & $9(16)$ & $3(8)$ & $6(30)$ & \\
\hline \multicolumn{5}{|l|}{ Age, years } \\
\hline$\leq 70$ & $7(13)$ & $5(14)$ & $2(10)$ & \multirow[t]{2}{*}{0.673} \\
\hline$>70$ & $49(87)$ & $31(86)$ & $18(90)$ & \\
\hline \multicolumn{5}{|l|}{ Tumor invasion } \\
\hline pT2 & $30(54)$ & $20(56)$ & $10(50)$ & \multirow[t]{2}{*}{0.690} \\
\hline pT3,4 & $26(36)$ & $16(44)$ & $10(50)$ & \\
\hline \multicolumn{5}{|c|}{ Lymph node status } \\
\hline No & $53(95)$ & $34(94)$ & $19(95)$ & \multirow[t]{2}{*}{0.930} \\
\hline $\mathrm{N} 1-3$ & $3(5)$ & $2(6)$ & $1(5)$ & \\
\hline \multicolumn{5}{|l|}{ pTNM stage } \\
\hline II & $29(52)$ & $10(50)$ & $19(53)$ & \multirow[t]{2}{*}{0.842} \\
\hline III-IV & $27(48)$ & $10(50)$ & $17(47)$ & \\
\hline
\end{tabular}

ESRRA: Estrogen-related receptor-alpha; pT: pathologic tumor stage; $\mathrm{N}$ : lymph node stage; pTNM: pathologic TNM stage.

$(4,5)$. In addition, in our study, we found that expression of ESRRA, which we identified to be a key coordinator of transcriptional and post-translational activation of autophagy in BMDMs, correlated with poor DFS, which supported the tumor-promoting role of ESRRA in various cancer types (14, 24). Interestingly, our study reported that all patients who showed low ESRRA and LC3B expression status on tumor tissue had a favorable 5-year DFS (84.2\%) and OS (81.6\%). In contrast with the double-negative expression group, the double-positive group showed extremely poor 5-year DFS $(26.7 \%)$ and OS (40\%). These rates were much lower than those of pTNM stage III groups, which were $55.8 \%$ and $63.4 \%$ (data not shown). These results suggested that a combination of these two markers provided additional prognostic information.

In previous studies, various autophagy markers used as immunohistochemistry can be helpful to predict treatment response and survival in various cancer. The absence of autophagy-related proteins such as ATG5, BECN1, and LC3B is associated with poor prognosis in patients with colorectal adenocarcinoma (25). In NSCLC, BECN1 and p62 expression was independent risk factors related to OS (26). Furthermore, the remaining tumor autophagy marker LC3B can predict relapse-free survival and OS in breast cancer patients treated with neoadjuvant chemotherapy (27). Additionally, a distinct globular pattern of LC3B expression was correlated with prognosis in esophageal adenocarcinoma (28). Our results provide additional information that ESRRA had a positive correlation with autophagy-related protein. Because the combination of ESRRA and LC3B can predict the DFS and OS in MIBC patients treated with partial or total cystectomy, they may help to refine our understanding of carcinogenesis and lead to more efficient treatment and evaluation strategies.

As is reported, ESRRA is an important regulator in tumor initiation and progression through the transcriptional control of cellular energy metabolism (24). The role of ESRRA in inducing transcriptional activation of its numerous target genes is regulated by its coexpression with PPARGC1A (peroxisome proliferative activated receptor, gamma, coactivator 1alpha) and SIRT1 (sirtuin-1) (29-31). These studies provide some evidence that ESRRA may be involved in autophagy signaling pathway, because PPARGC1A and SIRT1 play a critical role in autophagy pathway activation, thus being involved in a variety of biological processes (32-35). Recently, our study showed that ESRRA directly binds to the promoter regions of autophagy-related genes to induce their promoter activities, especially in response to AMPK or SIRT1 agonists (14). The aforementioned results are line with the current study showing that a moderate positive correlation exists between LC3B and ESRRA in bladder cancer specimens.

Taken together, we were able to make a reasonable hypothesis that ESRRA may be involved in autophagy pathway, which plays an important role in tumor progression and recurrence of bladder cancer. The addition of LC $3 B$ and ESRRA proteins to conventional prognostic factors may help to predict the treatment response and recurrence in bladder cancer. Evaluating LC3B and ESRRA proteins with current staging may help make precision medicine possible, which 

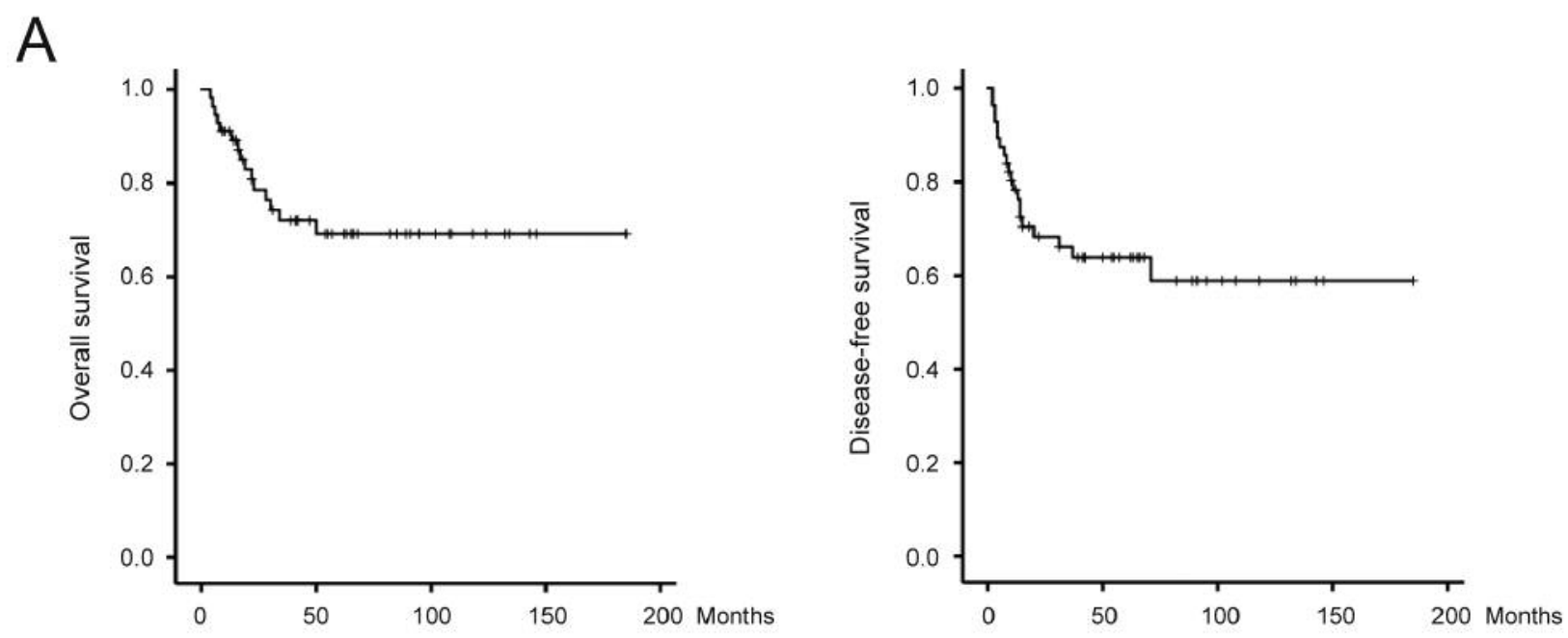

B
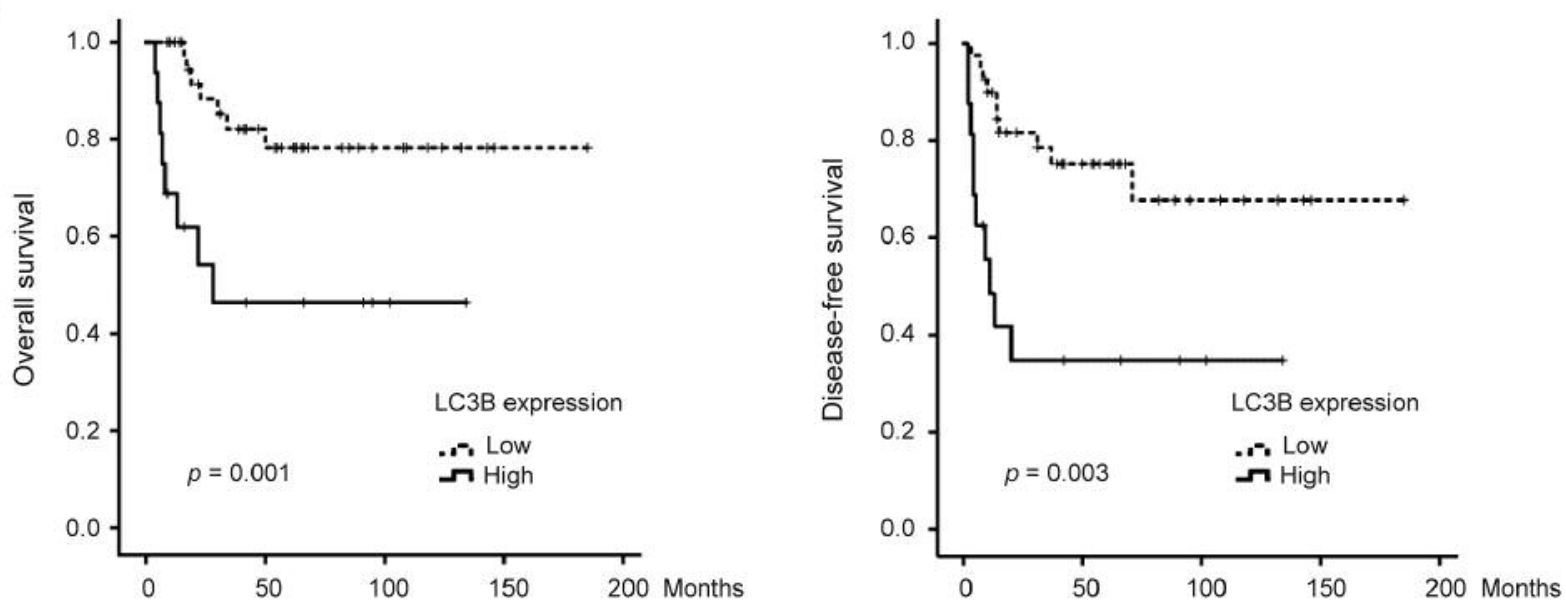

C
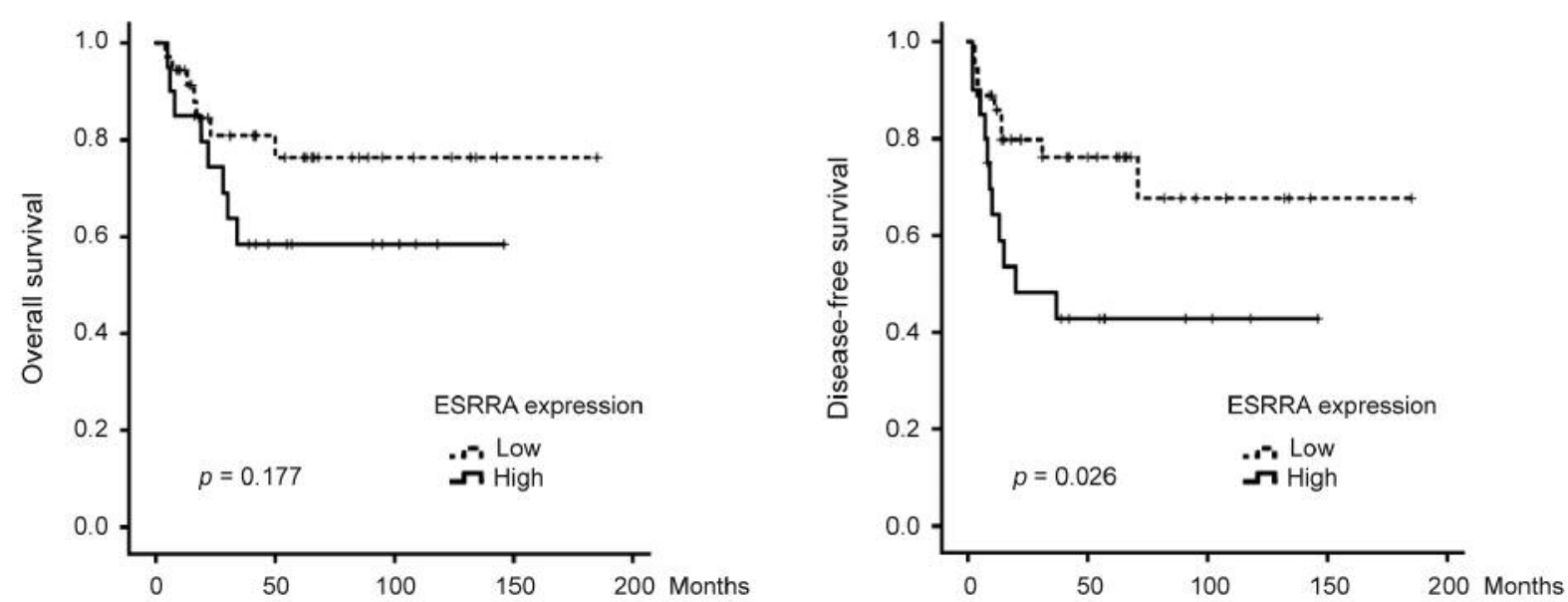

Figure 3. Survival curves for patients with bladder cancer according to LC3B and ESRRA expression. (A) OS and DFS for the entire patient cohort. $(B)$ and $(C)$ OS and DFS curves for the patients with MIBC, as stratified by LC3B and ESRRA expression. (B) Patients with high LC3B expression had shorter overall and disease-free survival times than those with low LC3B expression. (C) Patients with high ESSRA expression had shorter disease-free survival times than those with low ESSRA expression. 


\section{A}

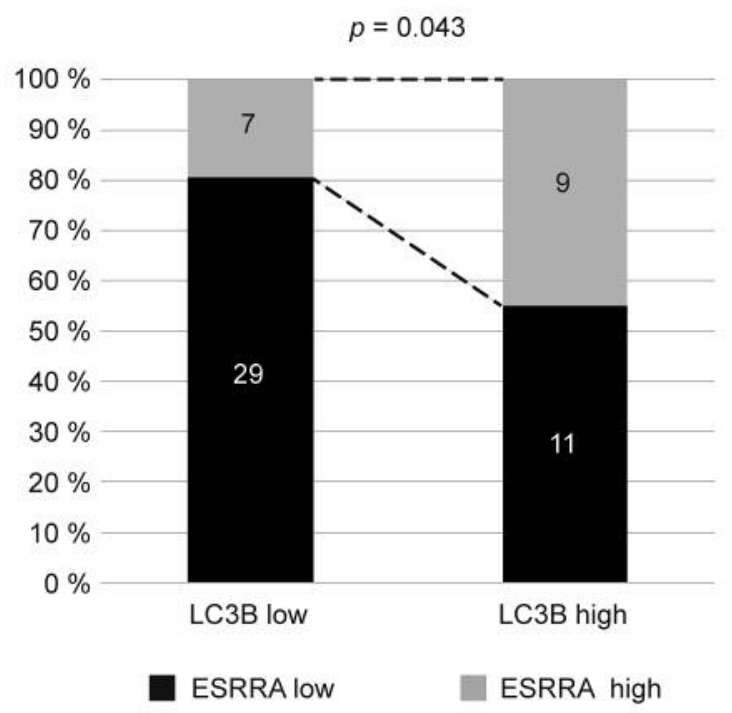

Figure 4. Correlation between LC3B and ESRRA in muscle-invasive bladder cancer. (A) A comparison between LC3B and ESRRA protein expression. Proportionately higher LC $3 B$ expression from high ESRRA group compared to low ESRRA group. (B) Kaplan-Meier curves for OS and DFS in bladder cancer patients according to according to the combination of $L C 3 B$ and ESRRA expression levels. Statistically significant differences were detected in three groups for OS and DFS.

minimizes over-treatment or under-treatment of MIBC. Therefore, our results may provide clinicians with additional diagnostic information with regard to predicting risk and deciding individualized treatment strategies after surgery for bladder cancer.

\section{Acknowledgements}

This work was supported by the National Research Foundation of Korea (NRF) grant funded by the Korean Government (MSIT) (No. 2017R1A5A2015385, 2017R1D1A1B04034379)

\section{References}

1 Siegel R, Naishadham D and Jemal A: Cancer statistics, 2012. CA Cancer J Clin 62: 10-29, 2012.

2 Meeks JJ, Bellmunt J, Bochner BH, Clarke NW, Daneshmand S, Galsky MD, Hahn NM, Lerner SP, Mason M, Powles T,
B
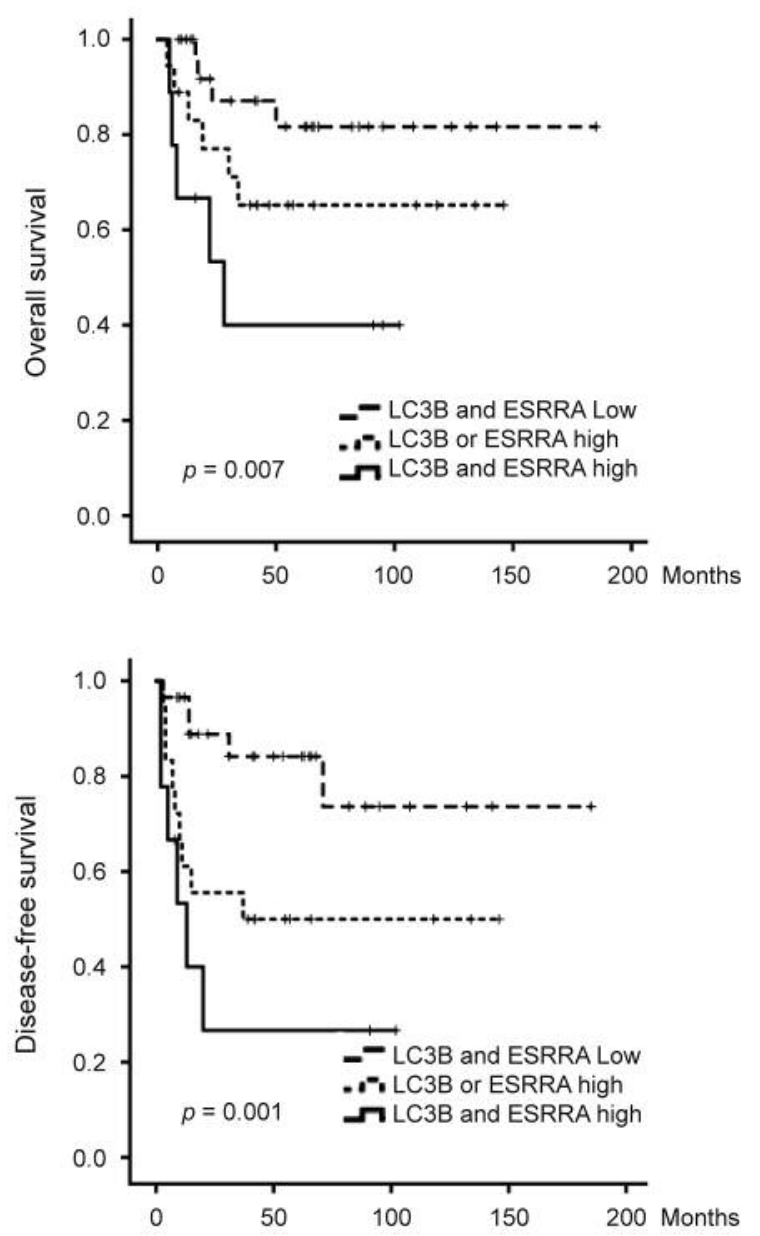

Sternberg CN and Sonpavde G: A systematic review of neoadjuvant and adjuvant chemotherapy for muscle-invasive bladder cancer. Eur Urol 62: 523-533, 2012.

3 Porter MP, Kerrigan MC, Donato BM and Ramsey SD: Patterns of use of systemic chemotherapy for Medicare beneficiaries with urothelial bladder cancer. Urol Oncol 29: 252-258, 2011.

4 Ojha R, Singh SK, Bhattacharyya S, Dhanda RS, Rakha A, Mandal AK and Jha V: Inhibition of grade dependent autophagy in urothelial carcinoma increases cell death under nutritional limiting condition and potentiates the cytotoxicity of chemotherapeutic agent. J Urol 191: 1889-1898, 2014.

5 Lin YC, Lin JF, Wen SI, Yang SC, Tsai TF, Chen HE, Chou KY and Hwang TI: Inhibition of High Basal Level of Autophagy Induces Apoptosis in Human Bladder Cancer Cells. J Urol 195: 1126-1135, 2016.

6 Baspinar S, Bircan S, Yavuz G and Kapucuoglu N: Beclin 1 and bcl-2 expressions in bladder urothelial tumors and their association with clinicopathological parameters. Pathol Res Pract 209: 418-423, 2013. 
7 Zhou F, Yang Y and Xing D: Bcl-2 and Bcl-xL play important roles in the crosstalk between autophagy and apoptosis. Febs $\mathrm{j}$ 278: 403-413, 2011.

8 Pattingre S, Tassa A, Qu X, Garuti R, Liang XH, Mizushima N, Packer M, Schneider MD and Levine B: Bcl-2 antiapoptotic proteins inhibit Beclin 1-dependent autophagy. Cell 122: 927939, 2005

9 Nakatogawa H, Suzuki K, Kamada Y and Ohsumi Y: Dynamics and diversity in autophagy mechanisms: lessons from yeast. Nat Rev Mol Cell Biol 10: 458-467, 2009.

10 Yang $\mathrm{Z}$ and Klionsky DJ: An overview of the molecular mechanism of autophagy. Curr Top Microbiol Immunol 335: 132, 2009.

11 Tanida I, Minematsu-Ikeguchi N, Ueno $\mathrm{T}$ and Kominami E: Lysosomal turnover, but not a cellular level, of endogenous LC3 is a marker for autophagy. Autophagy 1: 84-91, 2005.

12 Yoshioka A, Miyata H, Doki Y, Yamasaki M, Sohma I, Gotoh K, Takiguchi S, Fujiwara Y, Uchiyama Y and Monden M: LC3, an autophagosome marker, is highly expressed in gastrointestinal cancers. Int J Oncol 33: 461-468, 2008.

13 Klionsky DJ, Abeliovich H, Agostinis P, Agrawal DK, Aliev G, Askew DS, Baba M, Baehrecke EH, Bahr BA, Ballabio A, Bamber BA, Bassham DC, Bergamini E, Bi X, Biard-Piechaczyk M, Blum JS, Bredesen DE, Brodsky JL, Brumell JH, Brunk UT, Bursch W, Camougrand N, Cebollero E, Cecconi F, Chen Y, Chin LS, Choi A, Chu CT, Chung J, Clarke PG, Clark RS, Clarke SG, Clave C, Cleveland JL, Codogno P, Colombo MI, Coto-Montes A, Cregg JM, Cuervo AM, Debnath J, Demarchi F, Dennis PB, Dennis PA, Deretic V, Devenish RJ, Di Sano F, Dice JF, Difiglia M, DineshKumar S, Distelhorst CW, Djavaheri-Mergny M, Dorsey FC, Droge W, Dron M, Dunn WA Jr., Duszenko M, Eissa NT, Elazar Z, Esclatine A, Eskelinen EL, Fesus L, Finley KD, Fuentes JM, Fueyo J, Fujisaki K, Galliot B, Gao FB, Gewirtz DA, Gibson SB, Gohla A, Goldberg AL, Gonzalez R, Gonzalez-Estevez C, Gorski S, Gottlieb RA, Haussinger D, He YW, Heidenreich K, Hill JA, Hoyer-Hansen M, Hu X, Huang WP, Iwasaki A, Jaattela M, Jackson WT, Jiang X, Jin S, Johansen T, Jung JU, Kadowaki M, Kang C, Kelekar A, Kessel DH, Kiel JA, Kim HP, Kimchi A, Kinsella TJ, Kiselyov K, Kitamoto K, Knecht E, Komatsu M, Kominami E, Kondo S, Kovacs AL, Kroemer G, Kuan CY, Kumar R, Kundu M, Landry J, Laporte M, Le W, Lei HY, Lenardo MJ, Levine B, Lieberman A, Lim KL, Lin FC, Liou W, Liu LF, LopezBerestein G, Lopez-Otin C, Lu B, Macleod KF, Malorni W, Martinet W, Matsuoka K, Mautner J, Meijer AJ, Melendez A, Michels P, Miotto G, Mistiaen WP, Mizushima N, Mograbi B, Monastyrska I, Moore MN, Moreira PI, Moriyasu Y, Motyl T, Munz C, Murphy LO, Naqvi NI, Neufeld TP, Nishino I, Nixon RA, Noda T, Nurnberg B, Ogawa M, Oleinick NL, Olsen LJ, Ozpolat B, Paglin S, Palmer GE, Papassideri I, Parkes M, Perlmutter DH, Perry G, Piacentini M, Pinkas-Kramarski R, Prescott M, ProikasCezanne T, Raben N, Rami A, Reggiori F, Rohrer B, Rubinsztein DC, Ryan KM, Sadoshima J, Sakagami H, Sakai Y, Sandri M, Sasakawa C, Sass M, Schneider C, Seglen PO, Seleverstov O, Settleman J, Shacka JJ, Shapiro IM, Sibirny A, Silva-Zacarin EC, Simon HU, Simone C, Simonsen A, Smith MA, Spanel-Borowski K, Srinivas V, Steeves M, Stenmark H, Stromhaug PE, Subauste CS, Sugimoto S, Sulzer D, Suzuki T, Swanson MS, Tabas I, Takeshita F, Talbot NJ, Talloczy Z, Tanaka K, Tanaka K, Tanida I, Taylor GS, Taylor JP, Terman A, Tettamanti G, Thompson CB, Thumm M, Tolkovsky AM, Tooze SA, Truant R, Tumanovska LV,
Uchiyama Y, Ueno T, Uzcategui NL, van der Klei I, Vaquero EC, Vellai T, Vogel MW, Wang HG, Webster P, Wiley JW, Xi Z, Xiao G, Yahalom J, Yang JM, Yap G, Yin XM, Yoshimori T, Yu L, Yue Z, Yuzaki M, Zabirnyk O, Zheng X, Zhu X and Deter RL: Guidelines for the use and interpretation of assays for monitoring autophagy in higher eukaryotes. Autophagy 4: 151-175, 2008.

14 Kim SY, Yang CS, Lee HM, Kim JK, Kim YS, Kim YR, Kim JS, Kim TS, Yuk JM, Dufour CR, Lee SH, Kim JM, Choi HS, Giguere V and Jo EK: ESRRA (estrogen-related receptor alpha) is a key coordinator of transcriptional and post-translational activation of autophagy to promote innate host defense. Autophagy 25: 1-17, 2017.

15 Svatek RS, Shariat SF, Novara G, Skinner EC, Fradet Y, Bastian PJ, Kamat AM, Kassouf W, Karakiewicz PI, Fritsche HM, Izawa JI, Tilki D, Ficarra V, Volkmer BG, Isbarn H and Dinney CP: Discrepancy between clinical and pathological stage: external validation of the impact on prognosis in an international radical cystectomy cohort. BJU Int 107: 898-904, 2011.

16 Fan EW, Li CC, Wu WJ, Huang CN, Li WM, Ke HL, Yeh HC, Wu TF, Liang PI, Ma LJ and Li CF: FGF7 Over Expression is an Independent Prognosticator in Patients with Urothelial Carcinoma of the Upper Urinary Tract and Bladder. J Urol 194: 223-229, 2015.

17 Chang IW, Wang YH, Wu WJ, Liang PI, Li WM, Yeh BW, Wu TF, He HL, Huang SK and Li CF: Necdin Overexpression Predicts Poor Prognosis in Patients with Urothelial Carcinomas of the Upper Urinary Tract and Urinary Bladder. J Cancer 7: 304-313, 2016.

18 Ma LJ, Wu WJ, Wang YH, Wu TF, Liang PI, Chang IW, He HL and Li CF: SPOCK1 Overexpression Confers a Poor Prognosis in Urothelial Carcinoma. J Cancer 7: 467-476, 2016.

19 Wang YH, Wu WJ, Wang WJ, Huang HY, Li WM, Yeh BW, Wu TF, Shiue YL, Sheu JJ, Wang JM and Li CF: CEBPD amplification and overexpression in urothelial carcinoma: a driver of tumor metastasis indicating adverse prognosis. Oncotarget 6: 31069-31084, 2015.

20 Yeh CM, Chen PC, Hsieh HY, Jou YC, Lin CT, Tsai MH, Huang WY, Wang YT, Lin RI, Chen SS, Tung CL, Wu SF, Chang DC, Shen CH, Hsu CD and Chan MW: Methylomics analysis identifies ZNF671 as an epigenetically repressed novel tumor suppressor and a potential non-invasive biomarker for the detection of urothelial carcinoma. Oncotarget 6: 29555-29572, 2015.

21 Cardillo MR, Sale P and Di Silverio F: Heat shock protein-90, IL-6 and IL-10 in bladder cancer. Anticancer Res 20: 4579-4583, 2000.

22 Chang CH, Chan PC, Li JR, Chen CJ, Shieh JJ, Fu YC, Chen $\mathrm{HC}$ and $\mathrm{Wu} \mathrm{MJ}$ : Gab1 is essential for membrane translocation, activity and integrity of mTORCs after EGF stimulation in urothelial cell carcinoma. Oncotarget 6: 1478-1489, 2015.

23 Inoue S, Mizushima T, Fujita K, Meliti A, Ide H, Yamaguchi S, Fushimi H, Netto GJ, Nonomura N and Miyamoto H: GATA3 immunohistochemistry in urothelial carcinoma of the upper urinary tract as a urothelial marker and a prognosticator. Hum Pathol 64: 83-90, 2017.

24 Ranhotra HS: Estrogen-related receptor alpha and cancer: axis of evil. J Recept Signal Transduct Res 35: 505-508, 2015.

25 Choi JH, Cho YS, Ko YH, Hong SU, Park JH and Lee MA: Absence of autophagy-related proteins expression is associated with poor prognosis in patients with colorectal adenocarcinoma. Gastroenterol Res Pract 2014: 179586, 2014. 
26 Wang $\mathrm{X}, \mathrm{Du} \mathrm{Z}$, Li L, Shi M and Yu Y: Beclin 1 and p62 expression in non-small cell lung cancer: relation with malignant behaviors and clinical outcome. Int J Clin Exp Pathol 8: 1064410652, 2015.

27 Chen S, Jiang YZ, Huang L, Zhou RJ, Yu KD, Liu Y and Shao ZM: The residual tumor autophagy marker LC3B serves as a prognostic marker in local advanced breast cancer after neoadjuvant chemotherapy. Clin Cancer Res 19: 6853-6862, 2013.

28 El-Mashed S, O'Donovan TR, Kay EW, Abdallah AR, Cathcart MC, O'Sullivan J, O'Grady A, Reynolds J, O'Reilly S, O'Sullivan GC and McKenna SL: LC3B globular structures correlate with survival in esophageal adenocarcinoma. BMC Cancer 15: 582, 2015.

29 Huss JM, Torra IP, Staels B, Giguere V and Kelly DP: Estrogenrelated receptor alpha directs peroxisome proliferator-activated receptor alpha signaling in the transcriptional control of energy metabolism in cardiac and skeletal muscle. Mol Cell Biol 24: 9079-9091, 2004.

30 Torrano V, Valcarcel-Jimenez L, Cortazar AR, Liu X, Urosevic J, Castillo-Martin M, Fernandez-Ruiz S, Morciano G, CaroMaldonado A, Guiu M, Zuniga-Garcia P, Graupera M, Bellmunt A, Pandya P, Lorente M, Martin-Martin N, Sutherland JD, Sanchez-Mosquera P, Bozal-Basterra L, Zabala-Letona A Arruabarrena-Aristorena A, Berenguer A, Embade N, UgaldeOlano A, Lacasa-Viscasillas I, Loizaga-Iriarte A, Unda-Urzaiz M, Schultz N, Aransay AM, Sanz-Moreno V, Barrio R, Velasco G, Pinton P, Cordon-Cardo C, Locasale JW, Gomis RR and Carracedo A: The metabolic co-regulator PGC1alpha suppresses prostate cancer metastasis. Nat Cell Biol 18: 645-656, 2016.
31 Wilson BJ, Tremblay AM, Deblois G, Sylvain-Drolet G and Giguere V: An acetylation switch modulates the transcriptional activity of estrogen-related receptor alpha. Mol Endocrinol 24: 1349-1358, 2010.

32 Yang CS, Kim JJ, Lee HM, Jin HS, Lee SH, Park JH, Kim SJ, Kim JM, Han YM, Lee MS, Kweon GR, Shong M and Jo EK: The AMPK-PPARGC1A pathway is required for antimicrobial host defense through activation of autophagy. Autophagy 10: 785-802, 2014

33 Lee IH, Cao L, Mostoslavsky R, Lombard DB, Liu J, Bruns NE, Tsokos M, Alt FW and Finkel T: A role for the NAD-dependent deacetylase Sirt1 in the regulation of autophagy. Proc Natl Acad Sci USA 105: 3374-3379, 2008.

34 Sun T, Li X, Zhang P, Chen WD, Zhang HL, Li DD, Deng R, Qian XJ, Jiao L, Ji J, Li YT, Wu RY, Yu Y, Feng GK and Zhu XF: Acetylation of Beclin 1 inhibits autophagosome maturation and promotes tumour growth. Nat Commun 6: 7215, 2015.

35 Huang R, Xu Y, Wan W, Shou X, Qian J, You Z, Liu B, Chang C, Zhou T, Lippincott-Schwartz J and Liu W: Deacetylation of nuclear LC3 drives autophagy initiation under starvation. Mol Cell 57: 456-466, 2015.
Received January 5, 2018

Revised January 31, 2018

Accepted February 1, 2018 